\title{
Overview of pathogenesis of systemic sclerosis
}

\author{
D. J. Abraham ${ }^{1}$, T. Krieg ${ }^{2}$, J. Distler ${ }^{3}$ and O. Distler ${ }^{4}$
}

The aetiology of SSc is subject to ongoing research, as the precise events that underlie the development of this disease remain unclear. The pathogenesis is known to involve endothelium, epithelium, fibroblasts, innate and adaptive immune systems and their component immunological mediators. Endothelial cell damage may be the initiating factor, but the precise triggering event(s) remain elusive. Angiogenesis also appears to be dysregulated. Vasculopathy shows similarities in different organs (e.g. pulmonary arterial hypertension, renal disease, digital tip ulcers). Endothelin-1 is a potent mediator of vasculopathy, and hence represents a highly relevant target for intervention of vascular features in SSc.

KEY wORDS: Endothelial cell, Endothelin-1, Vasculopathy, Fibrosis, Scleroderma.

\section{Introduction}

The aetiology of SSc is currently an expanding area of study, since the exact nature of the events underlying this disease remains unclear [1]. SSc may be initiated in the vasculature, with evidence suggesting that some morphological changes may be apparent before disease onset [1]. The pathological events in SSc may include impaired communication between endothelial cells, epithelial cells and fibroblasts; lymphocyte activation; autoantibody production; inflammation; and connective tissue fibrosis [1]. These events result in an accumulation of constituents of the extracellular matrix (ECM), which replaces the normal tissue architecture, which in turn can culminate in organ failure. This review will focus on the potential role of the epithelium, and the roles of fibroblasts and immunological mediators in the pathogenesis of SSc. In addition, this review will consider the mediators of tissue remodelling, which are associated with the hallmark vasculopathy of SSc.

\section{The potential role of the epithelium}

The epithelium can be found widespread throughout the body, as the outer covering of the skin, and lining both internal organs and body cavities (e.g. mucous membranes, gut and lungs). Consequently, it has an extensive range of functions that include secretion, absorption, protection, transcellular transport, sensation detection and selective permeability. Following tissue injury, the epithelium plays a critical role in repairing wounds and re-surfacing tissue. In patients with $\mathrm{SSc}$, however, there is evidence that this regeneration may be dysregulated.

Many epithelial-derived factors influence the behaviour of fibroblasts, with some soluble mediators known to exhibit profibrotic activities, including TGF- $\beta$ and ET-1 (Table 1) [2, 3]. There is also evidence that epithelial-to-mesenchymal transdifferentiation (EMT) occurs in lung fibrosis $[4,5]$, and this process is known to be influenced or mediated by TGF- $\beta$, and potentially ET-1 [4-6].

During EMT, epithelial cells lose cell-cell attachment, alter polarity, display specific surface markers and can undergo

${ }^{1}$ Centre for Rheumatology and Connective Tissue Disease, Royal Free and University College Medical School, University College London, London, UK, ${ }^{2}$ Department of Dermatology, University of Cologne, Cologne, ${ }^{3}$ Department for Internal Medicine 3 and Institute for Clinical Immunology, Friedrich-AlexanderUniversity Erlangen-Nuremberg, Erlangen, Germany and ${ }^{4}$ Rheumaklinik und Institut fuer physikalische Medizin, University of Zurich, Zurich, Switzerland.

Submitted 30 January 2008; revised version accepted 1 December 2008.

Correspondence to: D. J. Abraham, Centre for Rheumatology and Connective Tissue Disease, Royal Free and University College Medical School, University College London, Hampstead Campus, Rowland Hill Street, Hampstead, London NW3 2PF, UK. E-mail: d.abraham @medsch.ucl.ac.uk cytoskeletal remodelling to exhibit a mesenchymal phenotype [4]. Studies in vitro have shown that alveolar epithelial cells can transdifferentiate into mesenchymal cells. Tissue staining and transgenic animal studies have shown that alveolar epithelial cells can co-express markers of both epithelial and mesenchymal cells, including cadherin and $\alpha$-smooth muscle actin ( $\alpha$-SMA) [5]. In addition, in the murine bleomycin-induced lung fibrosis model fibrosis is preceded by epithelial injury. These findings suggest that the epithelium might play an important role in the pathogenesis of SSc, at least for some specific organ manifestations such as lung fibrosis (Fig. 1).

\section{The role of fibroblasts and the immune system}

\section{The role of fibroblasts}

Fibroblasts maintain the structural integrity of connective tissue, secreting fibrillar procollagens, fibronectin and regulating the turnover and composition of the ECM via highly specific proteases such as collagenase. Different subtypes of fibroblasts exist and can perform a variety of functions in different locations (e.g. papillary fibroblasts, dermal papilla fibroblasts, myofibroblasts). Although morphologically similar, these different fibroblast subpopulations are distinguishable by their gene expression profiles and functional activities [7, 8]. For example, whilst papillary fibroblasts produce thin collagen bundles and have a high rate of proliferation, reticular fibroblasts produce thick collagen bundles and abundant versican, and promote rapid lattice contraction [9]. Following tissue injury, quiescent fibroblasts are activated during the wound healing and inflammation phase, producing granulation tissue and a provisional matrix, a process that is subsequently reversed to remodel the scar. In human disease, such as hypertrophic keloid scarring or SSc, this scar tissue is not correctly terminated or remodelled resulting in excessive scar formation.

Fibroblasts can be categorized according to different stages of differentiation [10], as well as their levels of collagen production [11]. In SSc patients, activated fibroblasts are responsible for the development of fibrosis and accumulation of ECM molecules. These fibroblasts are characterized by an overproduction of collagen and the induction of collagen-modifying enzymes.

The gene expression profile of fibroblasts is influenced by their environment [12]. For instance, quiescent fibroblasts express ET-1 and intercellular adhesion molecule-1, whereas the fibroblasts subject to mechanical stress may express $\alpha$-SMA, TGF- $\beta$ and ECM genes. The phenotype of SSc fibroblasts is comparable with that of fibroblasts that have been exposed to excessive signalling by TGF- $\beta$, which suggests a potential underlying mechanism $[13,14]$.

Activated fibroblasts may be derived from a number of origins. Precursor or progenitor cells may be recruited from the bone 
marrow or circulation, and resident cells may be recruited locally from the surrounding tissue. Although activated, these fibroblasts may not be terminally differentiated and in cell culture they can cease to exhibit an activated phenotype after several passages.

Activated fibroblasts in SSc may be derived from a number of origins [15]. Mesenchymal precursor cells may be recruited from the bone marrow via the circulation. Resident tissue-specific precursors may also be utilized from the surrounding tissue directly. Quiescent fibroblasts can be activated by different mechanism(s) including: (i) direct cell-cell contact, (ii) stimulation by soluble mediators following induction of the appropriate receptor expression-including TGF- $\beta$, connective tissue growth factor (CTGF), PDGF or ET-1 [13, 16, 17] — or by (iii) modulation of cell-matrix interactions. For example, ECM contraction modulates the activity of mediators such as TGF- $\beta$, and fibroblasts may also be activated by attachment to the ECM and the resultant mechanical tension, which can contribute to a persistent activation state [18]. Altered gene expression in SSc fibroblasts, such as the expression of cartilage oligomeric matrix protein and other key ECM components, is also likely to lead to a disturbed macromolecular arrangement of ECM molecules $[19,20]$. These findings suggest a major role for fibroblasts in the pathogenesis of SSc (Fig. 2).

TABLE 1. Key cytokines in the induction of the fibrosis of SSc

\begin{tabular}{ll}
\hline \multicolumn{1}{c}{ Mediator } & \multicolumn{1}{c}{ Role in fibrogenesis } \\
\hline TGF- $\beta$ & $\begin{array}{c}\text { ECM production, fibroblast proliferation } \\
\text { and differentiation } \\
\text { Regulation of fibroblast proliferation and migration } \\
\text { and TGF- } \beta \text {-dependent ECM synthesis } \\
\text { Regulation of ECM synthesis and contraction }\end{array}$ \\
ET-1 & $\begin{array}{l}\text { Regulation of fibroblast growth } \\
\text { Inflammatory mediator }\end{array}$ \\
Fibroblast growth factor & $\begin{array}{l}\text { Regulation of collagen synthesis } \\
\text { IL-1 }\end{array}$ \\
IL-4 & $\begin{array}{l}\text { Regulation of } \alpha \text {-SMA expression in myofibroblasts } \\
\text { IL-6 }\end{array}$ \\
IL-12 & $\begin{array}{l}\text { Induction of TGF- } \beta \\
\text { IL-13 }\end{array}$ \\
IL-17 & Inflammatast proliferation mediator and regulation of collagen \\
MCP-1 & synthesis \\
Regulation of collagen synthesis & Regulation of TGF receptor expression, and fibroblast \\
MCP-3 & and progenitor cell recruitment \\
PDGF &
\end{tabular}

\section{The role of immunological mediators}

The immune system is also implicated in the pathology of SSc. Activated lymphocytes and autoantibodies are detectable in SSc patients. Elevated levels of growth factors [including TGF- $\beta$, CTGF, vascular endothelial growth factor (VEGF), fibroblast growth factor], ILs (including IL-2, IL-4, IL-6, IL-10, IL-13), chemokines and cytokines [including monocyte chemoattractant protein-1 (MCP-1), IL-8, thymus and activationregulated chemokine, fractalkine and $\mathrm{TNF}-\alpha]$ are detectable in this disease.

In patients with $\mathrm{SSc}$, activated $\mathrm{T}$ lymphocytes are detectable in both the circulation and the affected organs (skin and lung). In the circulation, soluble IL-2 receptor levels correlate with the extent of skin fibrosis [21] and there is evidence for clonal expansion of $\mathrm{T}$ cells [22]. In the skin, oligoclonal expansion is observed [23], and there is enhanced transendothelial migration of $\mathrm{CD}^{+}{ }^{\mathrm{T}}$ cells [24].

The expression of CD19 on the circulating B cells of SSc patients may be increased [25], as may the expression of CD80 and CD86 on memory B cells [26]. Comparison of the cell type composition and gene expression profiles in skin biopsies from $\mathrm{SSc}$ patients with normal individuals has revealed clear differences, including infiltration of B lymphocytes into affected skin [19].

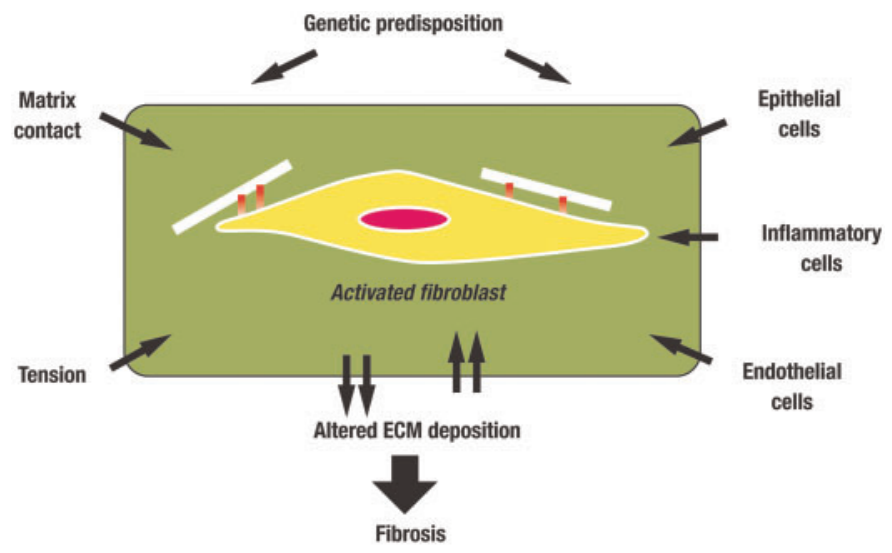

FIG. 2. The role of fibroblasts in the pathogenesis of SSc.

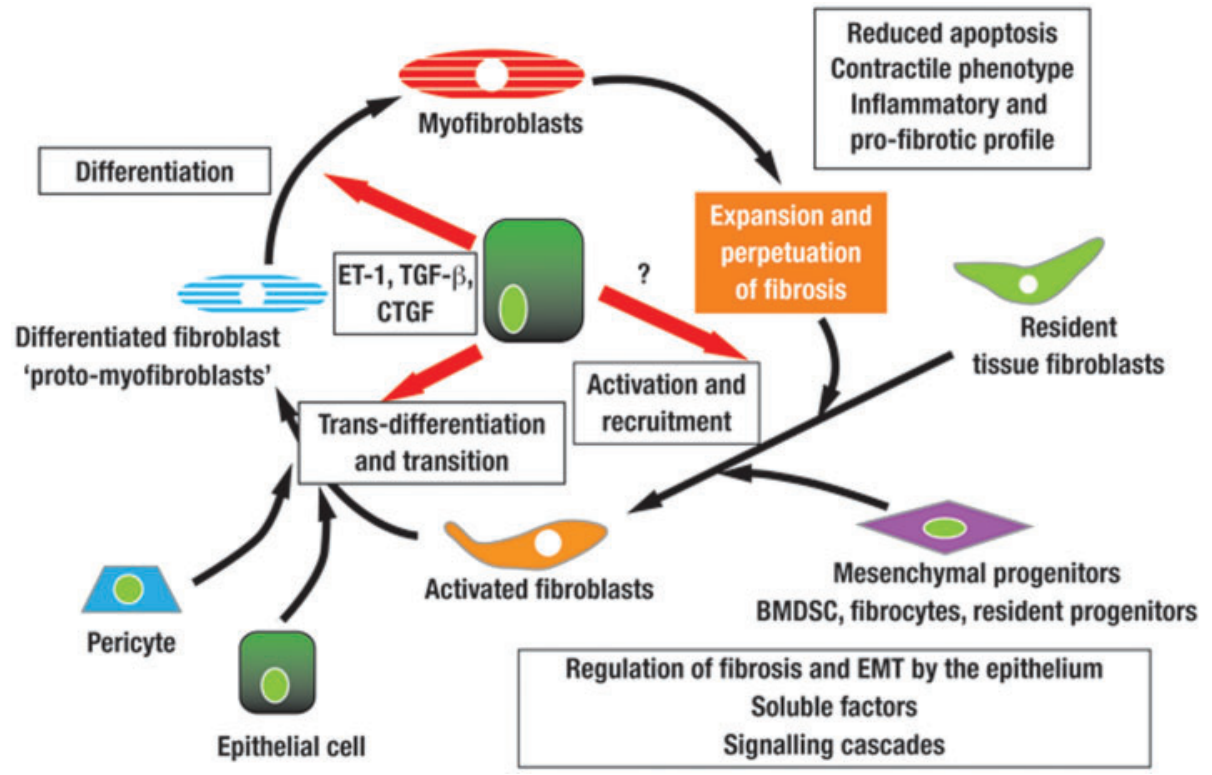

FIG. 1. The role of the epithelium in the pathogenesis of SSc. BMDSC: bone marrow-derived stem cells. 
In the tight skin mouse model of SSc, experimental B-cell depletion suppresses skin fibrosis and down-regulates Th2 cytokines in the skin [27], which suggests a pathological role for B cells in skin fibrosis.

The majority of patients with SSc exhibit circulating levels of highly specific autoantibodies: one autoantibody group is directed against nuclear antigens (topoisomerase, RNA polymerase), whereas others may have a putative pathogenic role. This latter group includes anti-endothelial cell antibodies, which are estimated to occur in $44-84 \%$ of SSc patients and may induce apoptosis [28-31]. Anti-fibrillin-1 antibodies are detectable in $>50 \%$ of SSc patients and can activate fibroblasts and stimulate release of TGF- $\beta$. Antibodies to MMP- 1 and -3 may also occur in a high proportion of patients, preventing the degradation of excessive collagen. Stimulatory anti-PDGF receptor antibodies are detectable in SSc patients and are potentially pathogenic [16]. These autoantibodies may stimulate normal fibroblasts via $\mathrm{Ha}-\mathrm{Ras}$ pathways, generate reactive oxygen species cascades to induce collagen I production and convert resting fibroblasts into activated myofibroblasts. Altered B-cell function may therefore be a key link between autoimmunity and fibrosis (Fig. 3).

\section{Vasculopathy in SSc}

In patients with SSc, vascular remodelling is dysregulated. In these patients, vasculopathy may result from a disrupted or inappropriate repair process following endothelial cell insult or injury. These patients may exhibit up-regulation of vasoconstrictive, thrombogenic, mitogenic and pro-inflammatory factors, and downregulation of vasodilatory, anti-thrombogenic and anti-mitogenic factors. This results in vasculopathy characterized by vasoconstriction, adventitial and intimal proliferation, inflammation and thrombosis.

Vasculopathy involves all layers of the vessel wall, and is characterized by fibrotic intimal hyperplasia [32]. As a result, vessels lose their elasticity and become narrower. In time, the arterial intima may thicken and occlusion of the small arteries can facilitate the formation of in situ thrombosis. Although the vasculopathy of SSc clearly shows organ-specific features, there are a number of similarities in the pathogenesis and morphology. Fibrosis typically begins in the media of medium-sized arteries, extending into the intima and adventitia and disrupting elasticity. The typical plexiform lesions of pulmonary arterial hypertension, comprising endothelial cells and myofibroblasts, can occur at all stages of development and healing. In renal arteries of patients with scleroderma renal crisis [33], there is the characteristic overgrowth of the endothelium and deposition of scar tissue in the blood vessels [34]. In digital ulceration associated with SSc, vascular remodelling leads to progressive occlusion of the blood vessels. Together with the reduced capillary density, this results in hypoxia, necrosis and tissue loss [35].

\section{The processes underlying vasculopathy}

Vascular remodelling appears to be preceded by endothelial dysfunction. Consistent evidence suggests that microvascular endothelial cell activation and damage is ubiquitous and occurs early in SSc. Activated endothelial cells express adhesion molecules, which, in part, promote perivascular inflammatory infiltrates by enabling the transmigration of inflammatory cells through the endothelium. Platelets are also activated.

The identity of the initial trigger remains elusive [36]. Hypotheses for the method of primary activation of endothelial cells in SSc include autoantibodies showing cross-reactivity between CMV epitopes and specific surface molecules of endothelial cells, inducing apoptosis. However, this is unlikely to be the sole aetiological factor, since CMV is ubiquitous in the normal population. Anti-endothelial cell antibodies can also activate endothelial cells, inducing the production of adhesion molecules and cytokines, such as IL-1 and TNF- $\alpha$. However, antiendothelial cell antibodies are detected in a variety of vascular diseases and specific epitopes and mechanisms have not been clarified in SSc. Oxidative stress and the presence of elevated levels of reactive oxygen species (ROS) has also been suggested to be an essential element in the early vascular pathogenesis in SSc, but the precise source of the ROS remains unknown.

Whatever the primary cause of the initial activation, ongoing activation inevitably results in endothelial cell damage. Apoptosis is an early event, and, if endothelial cells are not replaced by new cells, capillary breakdown and the typical clinical manifestations of vasculopathy can result.

A physiological reaction pattern to capillary breakdown and resulting tissue hypoxia is angiogenesis, a finely balanced process involving both angiogenic and angiostatic factors. In patients with SSc, angiogenesis becomes dysregulated. Angiogenic factors, including PDGF, VEGF, ET-1, TGF- $\beta$, MCP-1 and urokinasetype plasminogen activator receptors are up-regulated in SSc, despite the lack of sufficient angiogenic responses in ischaemic tissues of SSc patients.

VEGF is over-expressed throughout the dermis and epidermis, including fibroblasts and perivascular cells [37]. VEGF receptor-1 (VEGFR-1) and VEGFR-2 are also up-regulated [37]. However, while VEGF is one of the strongest angiogenic factors known in biology, its duration of expression is of critical importance: an uncontrolled, chronic over-expression, as in SSc, might lead to deleterious effects rather than promote the formation of new vessels. Alternatively, the up-regulated angiogenic factors could be overwhelmed by an even greater up-regulation of angiostatic

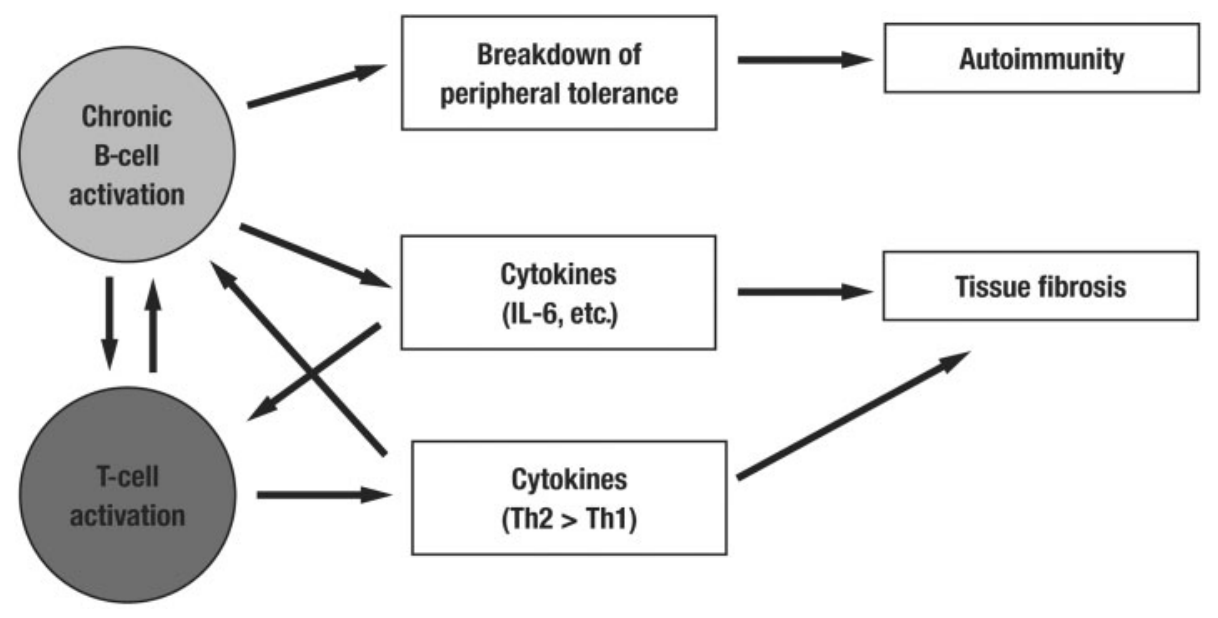

FIG. 3. The role of immunological mediators in the pathogenesis of SSc. 
factors, such as angiostatin and endostatin [38, 39]. At present, data describing the dysregulation of angiogenic homeostasis are incomplete and need further research.

\section{The relationship between blood vessels, endothelium and pericytes}

Small blood vessels comprise two cell types: endothelial cells and their attendant pericytes. To date, vascular research in SSc has been focused on the role of the endothelial cells in SSc pathogenesis, with the pericyte being largely overlooked. Microvascular pericytes are in intimate contact with, and modulate the function of, endothelial cells. They may also constitute a cellular link between microvascular damage and fibrosis by transdifferentiating into myofibroblasts [40]. In patients with SSc, pericytes are hyperplasic [41] and activated [40, 42]. Such pericytes may contribute to the overproduction of ECM molecules, and angiopoietin/Tie-2 signalling might be impaired.

\section{ET-1 as a molecular target for intervention in the management of patients with SSc}

ET-1 is a highly potent vasoconstrictor that is produced by endothelial cells and is a key mediator of vasculopathy. ET-1 promotes cell growth, arterial wall thickening and endothelial cell dysfunction, resulting in decreased levels of nitric oxide. ET-1 can stimulate the proliferation of pulmonary artery smooth muscle cells [43, 44], fibroblast collagen production, the down-regulation of MMP-1 and the contraction of fibroblast-populated collagen lattices; all of which suggest an important role in fibrosis. Increased ET-1 production can trigger an inflammatory cascade, elevating the plasma levels of pro-inflammatory cytokines in patients with pulmonary arterial hypertension [45]. Thus, ET-1 promotes vasoconstriction and contributes to cardiac and vascular hypertrophy, inflammation and fibrosis [46].

ET-1 is over-expressed in both early- and late-stage SSc [1]. Increased expression of ET-1 and ET-1 receptors is detectable in pre-sclerotic and early diffuse skin lesions [47], and elevated levels of ET-1 have been found in the blood vessels, lungs, kidneys and skin of SSc patients [48]. A role in the pathogenesis of SSc is suggested by the finding that circulating levels of ET-1 correlate with skin fibrosis and duration of disease [47].

ET-1 mediates its biological effects via the $\mathrm{ET}_{\mathrm{A}}$ and $\mathrm{ET}_{\mathrm{B}}$ receptors. $\mathrm{ET}_{\mathrm{A}}$ receptors are expressed by vascular smooth muscle cells and can mediate vasoconstriction, smooth muscle cell proliferation, fibrosis and inflammation. $\mathrm{ET}_{\mathrm{B}}$ receptors are predominantly expressed on endothelial cells; they can mediate vasodilation via the release of nitric oxide or potassium channel activation, and can remove ET-1 from the circulation. $\mathrm{ET}_{\mathrm{B}}$ receptors are also present on smooth muscle cells; however, in this localization they behave similarly to $\mathrm{ET}_{\mathrm{A}}$ receptors [49].

In vasculopathic conditions such as $\mathrm{SSc}, \mathrm{ET}_{\mathrm{B}}$ receptors are down-regulated on endothelial cells, which may diminish their vasodilatory role. On smooth muscle cells, $\mathrm{ET}_{\mathrm{B}}$ receptors are upregulated, and can contribute to cell proliferation, hypertrophy, inflammation, fibrosis and vasoconstriction $[48,50]$.

\section{Conclusion}

The pathogenesis of SSc is complex and appears to involve endothelium, epithelium, fibroblasts and immunological mediators, resulting in dysregulated vascular remodelling and, ultimately, vasculopathy. Endothelial cell injury is an early and probably initiating event, but the precise aetiology remains unclear. There are similarities between the vasculopathies of different organs, including pulmonary arterial hypertension, scleroderma renal crisis and digital ulcers, of which ET-1 is believed to be an important mediator. ET-1 is over-expressed in patients with $\mathrm{SSc}$, and its serum plasma concentrations correlate with markers of disease severity. ET-1 therefore represents an important molecular target for therapeutic intervention in the vascular disease manifestations of SSc.
- The pathogenesis of SSc involves epithelium, fibroblasts and immunological mediators.

- Endothelial cell damage is likely to be the initiating factor.

- ET-1 is a potent mediator of vasculopathy and a therapeutic target.

\section{Acknowledgements}

The authors received editorial assistance from Elements Communications, supported by an educational grant from Actelion Pharmaceuticals Limited (Allschwil, Switzerland).

Supplement: This paper forms part of the supplement entitled 'Ten years of partnership: translating ideas into progress in systemic sclerosis'. This supplement was supported by an unrestricted grant from Actelion Pharmaceuticals Ltd.

Disclosure statement: O.D. is a consultant for, has received support or honoraria from Actelion, Encysive, Array and Ergonex. J.D. is a member of a Speakers' Bureau for Actelion and Encysive and has received research grants/support from Novartis, Bristol-Myers Squibb and Celgene. D.J.A. has received speaker fees and travel expenses from Actelion Biopharmaceuticals and Encysive Pharmaceuticals. T.K. has received speaker fees and reimbursement for travel expenses from Actelion Pharmaceuticals Ltd and Encysive.

\section{References}

1 Abraham D, Distler O. How does endothelial cell injury start? The role of endothelin in systemic sclerosis. Arthritis Res Ther 2007;9(Suppl. 2):S2.

2 Shi-Wen X, Denton CP, Dashwood MR et al. Fibroblast matrix gene expression and connective tissue remodeling: role of endothelin-1. J Invest Dermatol 2001;116: 417-25.

3 Denton CP. Therapeutic targets in systemic sclerosis. Arthritis Res Ther 2007; 9(Suppl. 2):S6.

4 Willis BC, du Bois RM, Borok Z. Epithelial origin of myofibroblasts during fibrosis in the lung. Proc Am Thorac Soc 2006;3:377-82.

5 Kim KK, Kugler MC, Wolters PJ et al. Alveolar epithelial cell mesenchymal transition develops in vivo during pulmonary fibrosis and is regulated by the extracellular matrix. Proc Natl Acad Sci USA 2006;103:13180-5.

6 Jain R, Shaul PW, Borok Z, Willis BC. Endothelin-1 induces alveolar epithelialmesenchymal transition through endothelin type A receptor-mediated production of TGF-beta 1. Am J Respir Cell Mol Biol 2007;37:38-47.

7 Rinn JL, Bondre C, Gladstone HB, Brown PO, Chang HY. Anatomic demarcation by positional variation in fibroblast gene expression programs. PLoS Genet 2006; 2:e119.

8 Hinz B, Phan SH, Thannickal VJ, Galli A, Bochaton-Piallat ML, Gabbiani G. The myofibroblast: one function, multiple origins. Am J Pathol 2007;170:1807-16.

9 Sorrell JM, Caplan Al. Fibroblast heterogeneity: more than skin deep. J Cell Sci 2004;117:667-75.

10 Bayreuther K, Rodemann HP, Hommel R et al. Human skin fibroblasts in vitro differentiate along a terminal cell lineage. Proc Natl Acad Sci USA 1988;85:5112-6.

11 LeRoy EC. Increased collagen synthesis by scleroderma skin fibroblasts in vitro: a possible defect in the regulation or activation of the scleroderma fibroblast. J Clin Invest 1974;54:880-9.

12 Kessler-Becker D, Krieg T, Eckes B. Expression of pro-inflammatory markers by human dermal fibroblasts in a three-dimensional culture model is mediated by an autocrine interleukin-1 loop. Biochem J 2004;379:351-8.

13 Kawakami T, Ihn H, Xu W, Smith E, LeRoy C, Trojanowska M. Increased expression of TGF-beta receptors by scleroderma fibroblasts: evidence for contribution of autocrine TGF-beta signaling to scleroderma phenotype. J Invest Dermatol 1998; 110:47-51

14 Sonnylal S, Denton CP, Zheng B et al. Postnatal induction of transforming growth factor beta signaling in fibroblasts of mice recapitulates clinical, histologic, and biochemical features of scleroderma. Arthritis Rheum 2007:56:334-44.

15 Abraham DJ, Eckes B, Rajkumar V, Krieg T. New developments in fibroblast and myofibroblast biology: implications for fibrosis and scleroderma. Curr Rheumatol Rep 2007;9:136-43 
16 Baroni SS, Santillo M, Bevilacqua $\mathrm{F}$ et al. Stimulatory autoantibodies to the PDGF receptor in systemic sclerosis. N Engl J Med 2006;354:2667-76.

17 Chen Y, Shi-Wen X, Eastwood M et al. Contribution of activin receptor-like kinase 5 (transforming growth factor beta receptor type I) signaling to the fibrotic phenotype of scleroderma fibroblasts. Arthritis Rheum 2006;54:1309-16.

18 Wipff PJ, Rifkin DB, Meister JJ, Hinz B. Myofibroblast contraction activates latent TGF-1 from the extracellular matrix. J Cell Biol 2007;179:1311-23.

19 Whitfield ML, Finlay DR, Murray $\mathrm{Jl}$ et al. Systemic and cell type-specific gene expression patterns in scleroderma skin. Proc Natl Acad Sci USA 2003;100: 12319-24.

20 Gardner H, Shearstone JR, Bandaru R et al. Gene profiling of scleroderma skin reveals robust signatures of disease that are imperfectly reflected in the transcript profiles of explanted fibroblasts. Arthritis Rheum 2006;54:1961e-73.

21 Steen VD, Engel EE, Charley MR et al. Soluble serum interleukin 2 receptors in patients with systemic sclerosis. J Rheumatol 1996;23:646-9.

22 French LE, Lessin SR, Addya K et al. Identification of clonal T cells in the blood of patients with systemic sclerosis: positive correlation with response to photopheresis. Arch Dermatol 2001;137:1309-13.

23 Sakkas LI, Xu B, Artlett CM et al. Oligoclonal T cell expansion in the skin of patients with systemic sclerosis. J Immunol 2002;168:3649-59.

24 Stummvoll GH, Aringer M, Grisar J et al. Increased transendothelial migration of scleroderma lymphocytes. Ann Rheum Dis 2004;63:569-74.

25 Sato S, Hasegawa M, Fujimoto M et al. Quantitative genetic variation in CD19 expression correlates with autoimmunity. J Immunol 2000;165:6635-43.

26 Sato S, Fujimoto M, Hasegawa M, Takehara K. Altered blood B lymphocyte homeostasis in systemic sclerosis: expanded naive B cells and diminished but activated memory B cells. Arthritis Rheum 2004;50:1918-27.

27 Hasegawa M, Hamaguchi Y, Yanaba $\mathrm{K}$ et al. B-lymphocyte depletion reduces skin fibrosis and autoimmunity in the tight-skin mouse model for systemic sclerosis. Am J Pathol 2006;169:954-66.

28 Rosenbaum J, Pottinger BE, Woo P et al. Measurement and characterisation of circulating anti-endothelial cell IgG in connective tissue diseases. Clin Exp Immunol 1988;72:450-6.

29 Hill MB, Phipps JL, Cartwright RJ et al. Antibodies to membranes of endothelial cells and fibroblasts in scleroderma. Clin Exp Immunol 1996;106:491-7.

30 Salojin KV, Le Tonqueze M, Saraux A et al. Antiendothelial cell antibodies: useful markers of systemic sclerosis. Am J Med 1997;102:178-85.

31 Ahmed SS, Tan FK, Arnett FC et al. Induction of apoptosis and fibrillin 1 expression in human dermal endothelial cells by scleroderma sera containing anti-endothelial cell antibodies. Arthritis Rheum 2006;54:2250-62.

32 Humbert M, Morrell NW, Archer SL et al. Cellular and molecular pathobiology of pulmonary arterial hypertension. J Am Coll Cardiol 2004;43(12 Suppl. S):13S-24S

33 Penn $\mathrm{H}$, Howie AJ, Kingdon EJ et al. Scleroderma renal crisis: patient characteristics and long-term outcomes. Q J Med 2007;100:485-94.
34 Rhew EY, Barr WG. Scleroderma renal crises: new insights and developments. Curr Rheumatol Rep 2004;6:129-36.

35 LeRoy EC. Systemic sclerosis: a vascular perspective. Rheum Dis Clin North Am 1996;22:675-94.

36 Koch AE, Distler O. Vasculopathy and disordered angiogenesis in selected rheumatic diseases: rheumatoid arthritis and systemic sclerosis. Arthritis Res Ther 2007;(9 Suppl. 2):S3.

37 Distler O, Distler JH, Scheid A et al. Uncontrolled expression of vascular endothelial growth factor and its receptors leads to insufficient skin angiogenesis in patients with systemic sclerosis. Circ Res 2004;95:109-16.

38 Hebbar M, Peyrat JP, Hornez L, Hatron PY, Hachulla E, Devulder B. Increased concentrations of the circulating angiogenesis inhibitor endostatin in patients with systemic sclerosis. Arthritis Rheum 2000;43:889-93.

39 Distler O, Del Rosso A, Giacomelli R et al. Angiogenic and angiostatic factors in systemic sclerosis: increased levels of vascular endothelial growth factor are a feature of the earliest disease stages and are associated with the absence of fingertip ulcers. Arthritis Res 2002;4:R11.

40 Rajkumar VS, Howell K, Csiszar K et al. Shared expression of phenotypic markers in systemic sclerosis indicates a convergence of pericytes and fibroblasts to a myofibroblast lineage in fibrosis. Arthritis Res Ther 2005;7:R1113-23.

41 Helmbold P, Fiedler E, Fischer M, Marsch WC. Hyperplasia of dermal microvascular pericytes in scleroderma. J Cutan Pathol 2004;31:431-40.

42 Rajkumar VS, Sundberg C, Abraham DJ et al. Activation of microvascular pericytes in autoimmune Raynaud's phenomenon and systemic sclerosis. Arthritis Rheum 1999;42:930-41.

43 Hassoun PM, Thappa V, Landman MJ, Fanburg BL. Endothelin 1: mitogenic activity on pulmonary artery smooth muscle cells and release from hypoxic endothelial cells. Proc Soc Exp Biol Med 1992;199:165-70.

44 Stelzner TJ, O'Brien RF, Yanagisawa $\mathrm{M}$ et al. Increased lung endothelin-1 production in rats with idiopathic pulmonary hypertension. Am J Physiol 1992;262:L614-20.

45 Dorfmüller P, Perros F, Balabanian K, Humbert M. Inflammation in pulmonary arterial hypertension. Eur Respir J 2003;22:358-63.

46 Beghetti M, Black SM, Fineman JR. Endothelin-1 in congenital heart disease. Pediatr Res 2005;57:16R-20R

47 Vancheeswaran R, Magoulas T, Efrat G et al. Circulating endothelin-1 levels in systemic sclerosis subsets-a marker of fibrosis or vascular dysfunction? J Rheumatol 1994;21:1838-44.

48 Abraham DJ, Vancheeswaran R, Dashwood MR et al. Increased levels of endothelin-1 and differential endothelin type A and B receptor expression in scleroderma-associated fibrotic lung disease. Am J Pathol 1997;151:831-41.

49 Shetty SS, Okada T, Webb RL et al. Functionally distinct endothelin B receptors in vascular endothelium and smooth muscle. Biochem Biophys Res Commun 1993; 191:459-64.

50 Bauer M, Wilkens H, Langer F et al. Selective upregulation of endothelin B receptor gene expression in severe pulmonary hypertension. Circulation 2002;105:1034-6. 